\title{
Referral patterns after school medical examinations
}

\author{
R J RONA,* M ALLSOP, $\dagger$ R MORRIS, ${ }^{*}$ AND M MORGAN* \\ *Division of Community Health, United Medical and Dental Schools of Guy's and St Thomas's Hospitals \\ (St Thomas's Campus), and †West Lambeth Health Authority Community Health Services, South Western \\ Hospital, London
}

SUMmARY The incidence of sensory or language abnormalities and the factors influencing the clinical medical officers' decisions to refer children who failed developmental tests were studied. There were 1259 children examined and referrals for vision, hearing, and language assessment were made for $39(3 \cdot 1 \%), 75(6 \cdot 0 \%)$, and $27(2 \cdot 1 \%)$, respectively. About $80 \%$ of these problems, however, were not known to the child health services when the children were 3.5 years old, mainly because children had moved to the district after the age of 3.5 , and did not attend the 3.5 year screening clinics. Referrals formed only a small percentage of children who failed a test (11.0\% failed vision, $19.5 \%$ hearing, and $24.6 \%$ language assessments). For vision and hearing the most important reason for the discrepancy was the clinical medical officers' wish to reassess children who failed the test before referring them. For the language test the clinical medical officer's often believed that the screening did not reflect the child's skills, which suggests that language screening as currently used in the district is not effective. Evaluation of the examination has highlighted the need to review the tests being used.

A school entry medical examination takes place in most district health authorities. ${ }^{12}$ This is currently the only scheduled examination of primary school children and is a last chance to identify systematically undetected health problems that could affect the child's educational performance, ${ }^{2-4}$ although some would support regular screening (for example, for vision) during school years. ${ }^{5}$ It has been claimed that between 10 and $20 \%$ of children in Britain reach school with defects that should have been detected earlier. ${ }^{6}$ There is also a suspicion that examiners who identify a preschool child who has failed a test do not always take the required action. There is, however, little factual information to support these opinions, and explanations of why this might occur have not been established.

In West Lambeth Health Authority a precoded questionnaire recording the main examination results and referral details of those children whose school entry medical assessment was unsatisfactory has been used since 1984. Information about preschool examinations has been entered on to computer. We were therefore able to check whether those sensory or physical health problems identified in the school entry examination were previously known, and if not what the possible reasons were. We also explored the reasons why clinical medical officers did not refer children for further investigations when they failed tests according to pre-established thresholds.

\section{Subjects and methods}

Children attending the 42 primary schools covered by the West Lambeth Health Authority are routinely examined between the ages of 5.0 and 5.5 years. ${ }^{7}$ In the school year 1985-6 the tests included in the sensory and language assessments were: corrected and uncorrected distant vision for each eye (using the Snellen chart for distant vision), examination for squint, $25 \mathrm{~dB}$ sweep audiometry at seven frequencies for each ear, word discrimination tests of hearing (the Stycar 12 high frequency picture test and the Stycar low frequency picture test), and picture based tests of comprehension and expressive language. Many of the tests of hearing and language used in this district are associated with the child's educational performance at age $8 .^{7}$ The sweep audiometry and distant vision assessments are undertaken by the school nurses and the other tests are done by clinical medical officers. All the tests have been standardised and all the staff have undergone inservice training.

Vision, hearing, or language defects were defined 
as follows: for vision, an uncorrected acuity of $6 / 9$ or below in either eye, or corrected acuity of $6 / 9$ or below, or definite or doubtful squint. Hearing defects were defined as failures at three or more frequencies in the sweep audiometry in either ear, or refusal or unsatisfactory response to the high or low frequency pictures in either ear. Language defects were defined as a refusal or low scores for comprehension or expressive language, or unintelligible articulation.

Children were divided into three groups on the results of this assessment: those who failed a test and were referred to a specialist; those who failed a test but were not referred to a specialist, and those who did not fail the tests yet were referred to the specialist.

In the first group we were interested to assess whether the children's sensory or language problems were known to the community health service. This was checked with the information from the 3.5 year examination stored in the district computer. Data on examinations before the age of 3.5 were not available for this cohort of children. Two other items of information were used in this analysis; clinical medical officers' assessment at the age of 5 as to the age the detected problem was likely to have been present, and whether the child was previously living in the district.

In the second group we assessed possible reasons why the child was not referred despite failing a test (table 1). The clinical medical officers were sent a form to be completed for each child. Subsequently, among the children who failed a test, we compared

Table 1 Number of children not referred for reason given despite failing vision, hearing, or language assessment

\begin{tabular}{lccc}
\hline & $\begin{array}{l}\text { Vision } \\
(n=99)\end{array}$ & $\begin{array}{c}\text { Hearing } \\
(n=178)\end{array}$ & $\begin{array}{l}\text { Language } \\
(n=280)\end{array}$ \\
\hline $\begin{array}{l}\text { Screening not reflective of } \\
\text { child's skills }\end{array}$ & 1 & 5 & 121 \\
$\begin{array}{l}\text { Results doubtful-child to } \\
\text { be recalled }\end{array}$ & 43 & 75 & 26 \\
$\begin{array}{l}\text { Not severe enough to } \\
\text { need treatment }\end{array}$ & 6 & 2 & 38 \\
$\begin{array}{l}\text { Expected to improve } \\
\text { spontaneously }\end{array}$ & 0 & 10 & 24 \\
$\begin{array}{l}\text { Already under clinical } \\
\text { supervision }\end{array}$ & 16 & 14 & 10 \\
$\begin{array}{l}\text { Parent not present or } \\
\text { refuse referral }\end{array}$ & 2 & 7 & 1 \\
$\begin{array}{l}\text { Findings recorded wrongly } \\
\text { Child referred but not }\end{array}$ & 5 & 5 & 2 \\
recorded on form & 7 & 24 & 7 \\
$\begin{array}{l}\text { Child moved to another } \\
\text { school }\end{array}$ & 17 & 31 & 37 \\
Other reason & 2 & 5 & 14 \\
\hline
\end{tabular}

those who were referred and those who were not referred for each type of problem with respect to child's sex, whether the child was brought up in an English environment, which clinical medical officer carried out the examination, the severity of the sensory or language problem, and the cooperation of the child during the assessment. The degree of association was assessed using logistic regression analysis. ${ }^{8}$

The third group who were referred without failing a test was too small for analysis.

\section{Results}

In $1985-6$ a precoded form was completed for 1259 $(69 \%)$ of the 1825 eligible children. Of the children examined, $141(11.2 \%)$ were referred to a specialist, $571(45.4 \%)$ failed a relevant test and were not referred, and $22(1.7 \%)$ were referred despite no failure being recorded.

\section{AWARENESS OF SENSORY OR LANGUAGE PROBLEMS}

The figure shows the distribution of children referred for ophthalmic, audiological, or language assessment according to whether they had been living in the district, whether they had been seen at the age of 3.5 , and whether a problem had been identified at that time. Between a quarter and a third of these children did not live within the district health authority's area, and another third were not seen at the age of $3 \cdot 5$. Most of those seen had a previously identified problem. This was particularly the case for children referred for speech therapy.

\section{FACTORS AFFECTING THE REFERRAL PATTERN}

Table 1 shows the reasons why children who had failed a vision, hearing, or language test were not referred. The main reasons were that the screening did not reflect the child's skill, or the results were doubtful. Eighty five children had moved to another school so the follow up form could not be completed. Clinical medical officers often decided to recall children who failed vision, hearing, and language tests before deciding whether referral was necessary. Only for the language screening test, however, did they decide not to refer because they considered their findings did not reflect the child's real ability. Many children who failed the language test were not considered disabled enough for referral, or were expected to improve spontaneously.

In the analysis comparing the characteristics of those children who were referred and those who were not referred, those who were referred but for whom this fact was not recorded in the form were combined with those who had been referred, but those already receiving treatment were excluded 


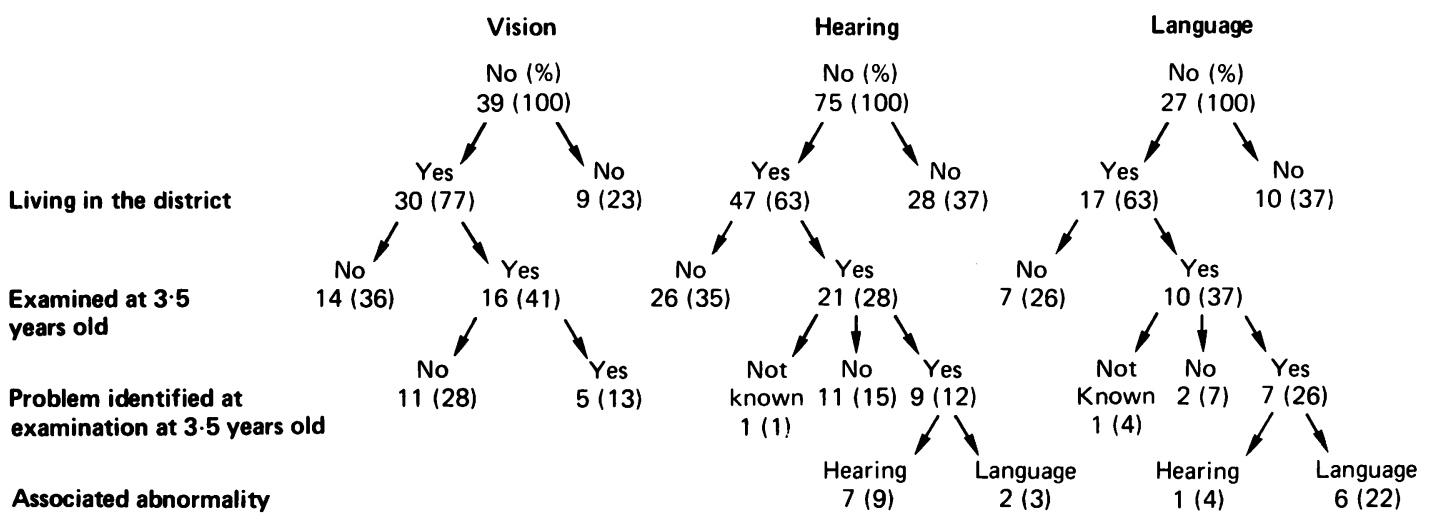

Figure Background information about children referred to a specialist because of a defect in vision, hearing, or language comprehension.

from the analysis (table 1). The small number of children who were referred whose test results were wrongly recorded as failures were included among those who were not referred. This group was not large enough to influence the results either way. Table 2 shows the percentages and $95 \%$ confidence intervals of probability of referral for speech therapy, or audiological and ophthalmic assessment. No significant differences were found regarding sex of the children, language spoken at home, and children's cooperation (but there were too few uncooperative children for analysis). The number of tests failed (a proxy measure of severity) was highly significantly associated with the probability of being referred for audiological assessment $(\mathrm{p}<0.001)$ and for ophthalmic assessment $(\mathrm{p}<0 \cdot 05)$. There was a trend with number of problems in the probability of referral to speech therapy but this was not significant. Significantly fewer children were referred who failed only the comprehension language test compared with those who failed the expressive language test, or both tests $(18.4 \%$ and $39.9 \%$, respectively). There were significant differences among examiners in their referral pattern to the three specialists. Some clinical medical officers consistently referred few children, others consistently referred a lot, and others referred proportionately more children with one type of abnormality than another.

Table 2 Probability of being referred if failing a test according to English environment, sex, number of failed assessments, and child's cooperation

\begin{tabular}{|c|c|c|c|c|c|c|}
\hline & \multicolumn{2}{|c|}{ Ophthalmology } & \multicolumn{2}{|l|}{ Audiology } & \multicolumn{2}{|c|}{ Speech therapy } \\
\hline & Total No & $\begin{array}{l}\% \text { Referred } \\
(2 S E)^{*}\end{array}$ & Total No & $\begin{array}{ll}\% & \text { Referred } \\
(2 & S E)^{*}\end{array}$ & Total No & $\begin{array}{ll}\% & \text { Referred } \\
(2 & S E)^{*}\end{array}$ \\
\hline $\begin{array}{l}\text { English environm } \\
\text { Yes } \\
\text { No }\end{array}$ & $\begin{array}{l}80 \\
46\end{array}$ & $\begin{array}{l}52.5(10 \cdot 9) \\
56.5(14 \cdot 3)\end{array}$ & $\begin{array}{r}183 \\
55\end{array}$ & $\begin{array}{l}50 \cdot 2(7 \cdot 2) \\
43 \cdot 6(13 \cdot 1)\end{array}$ & $\begin{array}{l}186 \\
111\end{array}$ & $\begin{array}{l}30 \cdot 1(6 \cdot 5) \\
32 \cdot 4(8 \cdot 7)\end{array}$ \\
\hline $\begin{array}{l}\text { Sex: } \\
\text { Boys } \\
\text { Girls }\end{array}$ & $\begin{array}{l}69 \\
59\end{array}$ & $\begin{array}{l}56 \cdot 5(11 \cdot 7) \\
50.9(12 \cdot 8)\end{array}$ & $\begin{array}{l}124 \\
114\end{array}$ & $\begin{array}{l}45 \cdot 2(8 \cdot 8) \\
52 \cdot 6(9 \cdot 2)\end{array}$ & $\begin{array}{l}157 \\
140\end{array}$ & $\begin{array}{l}33.8(7.4) \\
27.9(7.4)\end{array}$ \\
\hline $\begin{array}{l}\text { No of problems: } \\
1 \\
2 \\
3\end{array}$ & $\begin{array}{c}56 \\
68 \\
2+\end{array}$ & $\begin{array}{l}41.0(12.9) \\
64.7(11.4)\end{array}$ & $\begin{array}{r}107 \\
93 \\
38\end{array}$ & $\begin{array}{l}31 \cdot 8(8 \cdot 8) \\
52.7(10 \cdot 1) \\
86.8(10 \cdot 8)\end{array}$ & $\begin{array}{r}221 \\
49 \\
27\end{array}$ & $\begin{array}{l}28 \cdot 5(6 \cdot 0) \\
34 \cdot 7(13 \cdot 3) \\
44 \cdot 4(18 \cdot 7)\end{array}$ \\
\hline $\begin{array}{l}\text { Child's cooperati } \\
\text { Satisfactory } \\
\text { Unsatisfactory }\end{array}$ & $\begin{array}{l}122 \\
4 \dagger\end{array}$ & $53 \cdot 3(8.9)$ & $\begin{array}{r}224 \\
14\end{array}$ & $\begin{array}{l}47 \cdot 8(6 \cdot 5) \\
64 \cdot 2(25 \cdot 1)\end{array}$ & $\begin{array}{r}271 \\
26\end{array}$ & $\begin{array}{l}29.9(5 \cdot 5) \\
42 \cdot 3(17 \cdot 3)\end{array}$ \\
\hline
\end{tabular}

†Confidence interval not calculated for groups of less than 10 children.

$* \%$ Referred (2 SE) gives limits for $95 \%$ confidence interval. 


\section{Discussion}

The results of this study highlight the two main reasons for a child not having been previously found to have a sensory or language problem: the high percentage of children who only recently moved to the district, and the large percentage of children who were not examined at the age of $3 \cdot 5 .^{9}$ These two reasons explain about $66 \%$ of the undetected cases. Of those with a problem who were seen at the age of 3.5 years, half were first detected at that stage. A more specific problem concerning hearing is that hearing defects are often intermittent. For some of the newly detected children referred at the age of 5 the sensory problem may therefore be a new problem.

For the examination of vision the comparatively large percentage of children who were not identified as having a problem earlier may have been due less to the progressive nature of the disorder than to the recognised low sensitivity of the Stycar 5 letter test used at the age of 3.5 years. ${ }^{10}$ In this district there is a commitment to change the assessment test at the age of 3.5. This may become possible now that the Sonksen-Silver acuity letter match screening pack is available, which is a multiletter system.

Regarding language examination there were remarkably few children referred with a current language problem who were not identified as having the disorder at the age of 3.5 .

These results indicate that the families with young children who change address frequently pose a serious problem to an effective developmental screening programme in inner city areas in London. As it is known that most movers change address between neighbouring health authorities, the only possible way to keep track of these children would be through collaborative arrangements between authorities. This should include a commonly designed form with a clear summary to ensure that the personnel in each district become acquainted with their health needs.

Non-attendance for routine examinations tends to increase with age, and reflects the fact that a large percentage of parents of older children simply do not use these services. Health visiting would be the only way of reaching such children.

The proportion of children in the district failing tests according to the established norms was extremely high $(56 \cdot 7 \%)$. Figures obtained from the national child development studies (1958 cohort) on 7 year old children showed approximately $8 \%, 6 \%$, and $10-13 \%$ had defects in vision, hearing, and speech respectively, and speech problems increased two or three fold in social classes IV and V. ${ }^{11-13}$ In Lambeth, with a high incidence of social depriva- tion, and wide ethnic mix, the high rate of problems was not unexpected. In deciding whether a child should be referred, clinical medical officers seemed to be influenced by severity, measured by the number of failed tests. For language problems, however, undetected factors may have had an important influence on the examiners.

This study also indicates that language assessment at school medical examination needs a rigorous review, as only one in nine children who failed a test was referred and these children were only slightly less delayed than those who were not referred. There are insufficient speech therapists available in the district to cope with all 5 year old children who fail a test, and indeed it would be unwise to refer such a large number of children without a careful assessment of such a policy. Unfortunately few studies evaluating the usefulness of speech therapy seem to be available, despite the many methods available. ${ }^{14}$ There seem to be two options: if speech therapy were only effective when directed at individual children then school medical examinations should only aim to detect a small percentage (say $5 \%$ ) of children with severe speech problems. Alternatively if 'speech therapy' could be practiced on groups of children or speech therapists were able to train an intermediate group for more intensive treatment (for example, the children's parents or class teachers) then tests to identify the higher percentage of children with language delay would be justified. Any intervention should be shown to be effective in enabling the child to make better use of communication skills and educational opportunities. The number of children detected by any screening method should match the resources available for treating them.

In conclusion, this study shows that a large number of children with sensory or language defects were unknown to the community health services, mainly because a large number of these children were newcomers to the district, or did not attend the medical examination at the age of 3.5 years. The current tests to identify children with language delay are of limited help in deciding who should be referred, and they are currently being revised.

We thank everybody concerned with the school entry examination in the West Lambeth Health Authority, Professor W W Holland for his encouragement, Miss S Mandalia for her help and Mrs A Childs for her secretarial help. The study was supported by grants from the South East Thames Regional Health Authority and the DHSS.

\footnotetext{
References

${ }^{1}$ Stewart-Brown S, Haslum MN. Screening for hearing loss in childhood: a study of national practice. $\mathrm{Br}$ Med J 1987; 294:1386-8.

${ }^{2}$ Haines CR, Brown JB, Grantham EB, Rajagopolan VS,
} 
Sutcliffe PV. Neurodevelopmental screening in the school entrant medical examination as a predictor of coordination and communication difficulties. Arch Dis Child 1985;60:1122-7.

3 Baird G, Hall DMB. Developmental paediatrics in primary care: what should we teach? Br Med J 1985;291:583-6.

4 Peckham CS. Hearing impairment in childhood. Br Med Bull 1986;42:145-9.

5 Peckham CS. Vision in childhood. Br Med Bull 1986;42:150-4.

6 Editorial. Development screening. Lancet 1975;i:784-6.

7 Rona RJ, Allsop M, Morris RW. Monitoring the developmental examination schedule in an inner city health district. Child Care Health Dev 1987;13:329-40.

${ }^{8}$ Baker RJ, Nelder JA. The GLIM manual for release 3. Oxford: Numerical Algorithms Group, 1978.

9 Fraser RC. Patient movements and the accuracy of the age-sex register. J $R$ Coll Gen Pract 1982;32:615-22.

10 Shaw DE, Fielder AR, Minshull C, Rosenthal AR.
Amblyopia - factors influencing age of presentation. Lancet 1988;ii:207-9.

"Peckham CS, Sheridan M. Butler NR. School attainment of seven-year-old children with hearing difficulties. Dev Med Child Neurol 1972;14:592-602.

12 Alberman ED, Butler NR. Sheridan MD. Visual acuity in a national sample (1958 cohort) at seven years. Dev Med Child Neurol 1971;13:9-14.

13 Butler NR, Peckham C, Sheridan M. Speech defects in children aged 7 years: a national study. Br Med J 1973;i:253-7.

14 Howlin P. Language. In: Rutter M, ed. Developmental psychiatry. London: William Heineman, 1980:198-220.

Correspondence to Dr R J Rona, Department of Community Medicine, St Thomas's Campus, London SE1 7EH.

Accepted 6 December 1988 